\title{
Clinical effect of ticagrelor administered in acute coronary syndrome patients following percutaneous coronary intervention
}

\author{
YANJIAO LU* ${ }^{*}$ YANSHEN LI* ${ }^{*}$ RUI YAO, YAPENG LI, LING LI, LUOSHA ZHAO and YANZHOU ZHANG \\ Department of Cardiology, The First Affiliated Hospital of Zhengzhou University, Zhengzhou, Henan 450052, P.R. China
}

Received December 9, 2014; Accepted February 25, 2016

DOI: $10.3892 /$ etm.2016.3224

\begin{abstract}
The aim of the present study was to retrospectively analyze the clinical effect and safety of ticagrelor administration in acute coronary syndrome (ACS) patients following percutaneous coronary intervention (PCI). In total, 203 patients were enrolled, who were confirmed with ACS between March 2013 and May 2013, and had successfully undergone PCI. The patients were randomly divided into two groups, including the clopidogrel (group $\mathrm{A}, \mathrm{n}=108$ ) and ticagrelor groups (group $\mathrm{B}, \mathrm{n}=95$ ). Patients in group A were treated with a $600 \mathrm{mg}$ loading dose of clopidogrel followed by $75 \mathrm{mg} /$ day clopidogrel plus $100 \mathrm{mg} /$ day aspirin. Patients in group B received a $180 \mathrm{mg}$ loading dose of ticagrelor followed by $90 \mathrm{mg}$ ticagrelor twice daily plus $100 \mathrm{mg} /$ day aspirin. Light transmission aggregometry was performed to measure the platelet aggregation rate prior to and following 4 weeks of anti-platelet drug treatment. In addition, the rate of cardiovascular events and the adverse drug reactions were recorded within a 1-year treatment period. Compared with the clopidogrel group, the rate of recurrent angina in the ticagrelor group was significantly lower $(\mathrm{P}=0.05)$. However, the rate of dyspnea in the ticagrelor group was significantly higher when compared with that in the clopidogrel group $(\mathrm{P}=0.03)$. After 4 weeks of treatment, the reduction in the platelet aggregation rate was significantly different between the two groups $(\mathrm{P}<0.05)$. Therefore, ticagrelor, which is a novel antiplatelet aggregation drug, may reduce the rate of the adverse cardiovascular events in ACS patients following PCI, but a higher incidence of side-effects, such as dyspnea, may be observed.
\end{abstract}

Correspondence to: Professor Yanzhou Zhang, Department of Cardiology, The First Affiliated Hospital of Zhengzhou University, 1 Jian-She-Dong Road, Zhengzhou, Henan 450052, P.R. China E-mail: zhangyanzhou2050@sina.com

*Contributed equally

Key words: platelet aggregation rate, acute coronary syndrome, ticagrelor, clopidogrel

\section{Introduction}

Acute coronary syndrome (ACS) has evolved as an operational term that refers to a spectrum of conditions compatible with acute myocardial ischemia and/or infarction due to an abrupt reduction in coronary blood flow (1). It is estimated that in the USA each year, $>780,000$ individuals will experience ACS (2). The primary symptom associated with ACS is chest pain ('pain' includes symptoms such as discomfort, pressure and a squeezing sensation) (3-6). Common treatments of ACS include anti-ischemic therapy with nitrates, beta-adrenergic blockers, calcium channel blockers or acetylcholinesterase inhibitors, cholesterol management with statins, anticoagulant therapy with enoxaparin, and anti-platelet therapy with aspirin and a P2Y12 receptor inhibitor (7-13). Both clopidogrel and ticagrelor are $\mathrm{P} 2 \mathrm{Y} 12$ receptor inhibitors, however ticagrelor is a reversible and direct-acting oral antagonist of the ADP receptor P2Y12. Compared with clopidogrel, ticagrelor has a more rapid and consistent onset of action and, because it is reversible, it has a faster recovery of platelet function (14). The main pathophysiological mechanism of ACS involves the development of acute thrombosis subsequent to atherosclerotic plaque rupture, with activated platelets serving a key role in this process (15). Consequently, anti-platelet therapy for ACS is of high importance. Thus far, clopidogrel plus aspirin has been used as the standard treatment to prevent the recurrence of cardiovascular diseases $(16,13)$. Although dual anti-platelet therapy is administered, certain cardiovascular events can still occur, with the most severe manifestation being stent thrombosis (17).

Previous studies have identified that cardiovascular events are associated with clopidogrel resistance (18). Ticagrelor, an oral reversible P2Y12 receptor inhibitor, has been demonstrated to decrease the atherosclerotic thrombosis by inhibiting the formation of new blood clots (19). Few studies have investigated the clinical effect of ticagrelor to date, including the PLATO study. The PLATO study demonstrated that in patients with ACS, treatment with ticagrelor compared with clopidogrel significantly reduced the rate of mortality from vascular causes, myocardial infarction or stroke (20). However, a number of patients enrolled in the PLATO study were from North America. The aim of the present study was to investigate the clinical effect of ticagrelor in Asian patients.

In the present retrospective study, the effect and safety of ticagrelor administration following percutaneous coronary 
intervention (PCI) were investigated in ACS patients diagnosed between March 2013 and May 2014.

\section{Patients and methods}

Patients. A total of 203 patients (112 males and 91 females), who were diagnosed with ACS between March 2013 and May 2013 at the Department of Cardiology of The First Affiliated Hospital of Zhengzhou University (Zhengzhou, China) and successfully underwent PCI, were enrolled into the present study. ACS was diagnosed according to the American College of Cardiology/American Heart Association (ACC/AHA) and World Health Organization criteria (20). Patients with one or more of the following diseases were excluded from the study: Severe heart failure (New York Heart Association functional class III-IV) (21); hemorrhagic disease; severe hepatic and renal dysfunction; intolerance to anti-platelet drugs; and uncooperative patients due to severe mental or neurological diseases. All procedures were approved by the Ethics Committee of The First Affiliated Hospital of Zhengzhou University. Informed consent was obtained from all patients or their families.

Medication and PCI. The 203 ACS patients that had undergone PCI were randomly divided into the clopidogrel (group A, $\mathrm{n}=108$ ) and ticagrelor groups (group $\mathrm{B}, \mathrm{n}=95$ ). The duration of PCI was between $65 \mathrm{~min}$ and $3 \mathrm{~h}$, and unfractionated heparin (100 IU/kg; Anhui BBCA Pharmaceutical Co., Ltd., Hefei, China) was used. Drug-eluting stents, supplied by MicroPort Medical (Shanghai) Co.,Ltd. (Shanghai, China), were implanted in patients with severe angina or acute myocardiol infarction. During PCI, the blood flow was evaluated according to the Thrombolysis In Myocardial Infarction (TIMI) score (22), which was primarily used to assess distal coronary flow. In addition, the SYNTAX (Synergy Between Percutaneous Coronary Intervention With TAXUS and Cardiac Surgery) score was calculated during PCI to guide the choice of revascularization (23). In group A, the patients received clopidogrel (Sanofi-Aventis, Paris, France) in a loading dose of $600 \mathrm{mg}$, followed by a dose of $75 \mathrm{mg}$ plus $100 \mathrm{mg}$ aspirin daily. Patients in group B received ticagrelor (AstraZeneca, London, UK) at a loading dose of $180 \mathrm{mg}$, followed by a dose of $90 \mathrm{mg}$ twice daily plus $100 \mathrm{mg}$ aspirin daily. Treatments were administered for up to 12 months to patients with ACS without contraindications. ACS patients complicated with hypertension, hyperlipidemia or diabetes received corresponding reasonable treatment. For patients with hypertension, several classes of drugs including angiotensin converting enzyme inhibitors, $\beta$-blockers, calcium channel blockers and diuretics were administered to decrease blood pressure; drugs were chosen according to the level of blood pressure. Rosuvastatin (10 mg/day; AstraZeneca) was administered to patients with hyperlipidemia. In addition, patients with diabetes were treated with oral antidiabetic drugs or insulin, according to blood sugar level.

Outcome measurement and follow-up. The patients were followed up as inpatients or outpatients at the following time points: Pre-treatment, and 1, 3, 6 and 12 months after PCI. The examinations performed included complete blood count and blood biochemical tests at all time points. Patients were also followed up by telephone in order to record any main cardiovascular events and adverse drug reactions, including recurrent angina, recurrent myocardial infarction, stent thrombosis, stent restenosis, hemorrhage, dyspnea, mortality, transient ischemic attack, erythra and diarrhea. Furthermore, coronary artery angiography (Allura Xper FD 10/10; Philips Healthcare, Andover, MA, USA) was performed in all patients 12 months after PCI to determine the severity of coronary lesions and stent restenosis.

Platelet aggregation rate. Light transmission aggregometry (540VS aggregometer; Chronolog Corp., Havertown, PA, USA) was adopted to measure the platelet aggregation rates prior to and following 4-week treatment with anti-platelet drugs. Fasting vein blood samples $(5 \mathrm{ml})$ collected in the morning were centrifuged for $8 \mathrm{~min}$ at a speed of $81 \mathrm{x} \mathrm{g}$ in order to isolate the platelet-rich plasma (PRP). Subsequent to the first step, the remaining blood samples were centrifuged for $10 \mathrm{~min}$ at a speed of $1308 \mathrm{x} g$ to obtain the platelet-poor plasma (PPP), which was used to contrast with the PRP. The 8-min maximum platelet aggregation rate was tested by loading the PRP sample in the tank of the optical platelet aggregation analyzer and adding adenosine diphosphate (ADP) to a final concentration of $5 \mu \mathrm{mol} / 1$. The rate was compared with the PPP sample value, which was set as the blank control.

Statistical analysis. All statistical analyses were performed using SPSS version 17.0 for Windows (SPSS, Inc., Chicago, IL, USA). Continuous variables are presented as the mean \pm standard deviation, while categorical data are presented as numbers and percentages. The platelet aggregation rate prior to and following 4 weeks of treatment with anti-platelet drugs were compared using paired t-test, while the platelet aggregation rate between the two groups was compared by two independent samples t-test. The same measurement data at different time points were compared by analysis of variance for repeated measurement design. In order to compare frequencies among the two study groups, the $\chi^{2}$ test was used. All the calculated $\mathrm{P}$-values were two-tailed, and $\mathrm{P} \leq 0.05$ was considered to indicate a statistically significant difference.

\section{Results}

Patient baseline and procedural characteristics. There were no significant differences between the two groups in baseline patient characteristics, including clinical status, cardiovascular risk factors and medication use (Table I), or in angiographic or procedural characteristics, including the number and coronary artery location of stenosis, the number of drug-eluting stents implanted, angiography time, contrast dose used, TIMI flow and number of stents implanted (Table II).

Cardiovascular events and side effects. As shown in Table III, a small number of cardiovascular events and side effects occurred during the 1-year follow-up of patients treated with clopidogrel (group A) or ticagrelor (group B) subsequent to PCI. The rate of recurrent angina in the ticagrelor group was found to be significantly lower compared with that in the clopidogrel group $(\mathrm{P}=0.05)$, suggesting that ticagrelor may be a more effective drug for patients with ACS. In addition, 
Table I. Patient characteristics.

\begin{tabular}{|c|c|c|c|}
\hline Variable & Group A $(n=108)$ & Group B $(n=95)$ & P-value \\
\hline \multicolumn{4}{|l|}{ General status } \\
\hline Male gender, n (\%) & $60(55.6)$ & $52(54.7)$ & 0.91 \\
\hline Age, years & $59.63 \pm 9.88$ & $59.25 \pm 9.63$ & 0.78 \\
\hline \multicolumn{4}{|l|}{ Risk factors, n (\%) } \\
\hline Hypertension & $42(38.9)$ & $33(34.7)$ & 0.54 \\
\hline Hyperlipidemia & $36(33.3)$ & $29(30.5)$ & 0.67 \\
\hline Diabetes & $32(29.6)$ & $24(25.3)$ & 0.49 \\
\hline Smoking & $20(18.5)$ & $17(17.9)$ & 0.91 \\
\hline \multicolumn{4}{|l|}{ Clinical data } \\
\hline LVEF, \% & $45.61 \pm 1.65$ & $45.89 \pm 1.48$ & 0.20 \\
\hline Myocardial infarction, n (\%) & $16(14.8)$ & $14(14.7)$ & 0.99 \\
\hline \multicolumn{4}{|l|}{ Medication, n (\%) } \\
\hline Statins & $102(94.4)$ & $91(95.8)$ & 0.91 \\
\hline$\beta$-blockers & $95(88.0)$ & $82(86.3)$ & 0.73 \\
\hline ACEI & $79(73.1)$ & $78(82.1)$ & 0.13 \\
\hline
\end{tabular}

Results are expressed as the mean \pm standard deviation. LVEF, left ventricular ejection fraction; ACEI, angiotensin converting enzyme inhibitors.

the rate of dyspnea in the ticagrelor group was significantly higher compared with that observed in the clopidogrel group $(\mathrm{P}=0.03$; Table III). However, the majority of episodes lasted for $<1$ week, and patients were able to tolerate it and agreed to continue the treatment. No other statistically significant differences were observed in the number of other cardiovascular events or side effects between the two groups $(\mathrm{P}>0.05)$. In addition, a total of 17 and 16 adverse events were observed in groups A and B, respectively, with no statistically significant difference observed $(\mathrm{P}>0.05)$.

Platelet aggregation rate. As shown in Table IV, the platelet aggregation rate of the two groups was found to evidently decrease following 4 weeks of anti-platelet treatment, with a statistically significant difference observed when compared with the rate prior to treatment. Furthermore, the platelet aggregation rate of ticagrelor group showed a greater decrease when compared with that in the clopidogrel group $(\mathrm{P}<0.05)$.

Laboratory tests. As shown in Tables V and VI, the laboratory test results at various time points (pre-treatment, and after 1 , 3, 6 and 12 months of treatment) during the 1-year follow-up evaluation were not found to be significantly different (time-dependent effect, $\mathrm{P}>0.05$ ). In particular, the number of platelets prior to treatment was not evidently different when compared with that after treatment for various lengths of time. In addition, compared with the clopidogrel group, the laboratory test results of the ticagrelor group did not present statistically significant differences (main treatment effect, $\mathrm{P}>0.05$ ). Furthermore, the time trend between the two groups did not present significant differences between the two groups (interaction effect, $\mathrm{P}>0.05$ ), indicating the ticagrelor has a stronger effect on anti-platelet aggregation.

\section{Discussion}

ACS is one of the most common cardiovascular emergencies with a considerably high morbidity and mortality. Although ACS patients currently receive dual anti-platelet therapy following successful PCI, a number of patients still suffer from cardiovascular events (24). Recent studies have indicated that this is closely associated with clopidogrel resistance. Clopidogrel is a type of pro-drug that requires cytochrome P450 to induce its anti-platelet activity, and its combination with ADP receptor P2Y12 is irreversible (25). The aforementioned limitations promote the development of a novel P2Y12 receptor antagonist, such as ticagrelor. Ticagrelor results in reversible inhibition on $\mathrm{P} 2 \mathrm{Y} 12$; it is a reversible and direct-acting oral antagonist of the ADP receptor P2Y12, and provides faster, greater, and more consistent P2Y12 inhibition than clopidogrel $(26,27)$. A recent large-scale clinical trail aimed on the comparison of clopidogrel and ticagrelor in patients with ACS revealed that ticagrelor evidently decreased the mortality of patients with ACS and the recurrence of cardiovascular events (28). The 2012 ACC Foundation/AHA guidelines for the management of patients with unstable angina/non-ST-elevation myocardial infarction have recommended ticagrelor as an alternative medicine to clopidogrel (recommendation level Ib) (1). However, only a limited number of studies have investigated the clinical effect of ticagrelor to date.

In the present study, adverse events were found to occur in the two treatment groups in the 1-year follow-up after PCI. However, the incidence of recurrent angina in the ticagrelor group was significantly lower when compared with that in the clopidogrel group $(\mathrm{P}=0.05)$. After 4 -week drug treatment, the platelet aggregation rate of the ticagrelor group was decreased to a greater extent compared with the decrease observed in 
Table II. Details of coronary angiography and PCI procedures.

\begin{tabular}{|c|c|c|c|}
\hline Variable & Group A $(n=108)$ & Group B (n=95) & P-value \\
\hline \multicolumn{4}{|l|}{ Coronary arteries with stenosis, n (\%) } \\
\hline Left circumflex artery & $14(13.0)$ & $14(14.7)$ & 0.72 \\
\hline Left anterior descending artery & $59(54.6)$ & 49 (51.6) & 0.66 \\
\hline Right coronary artery & $25(23.1)$ & $22(23.2)$ & 1.00 \\
\hline Multi-artery stenosis & $10(9.3)$ & $10(10.5)$ & 0.76 \\
\hline \multicolumn{4}{|l|}{ Types of lesions (AHA/ACC), n (\%) } \\
\hline A & $32(29.6)$ & $28(29.5)$ & 0.98 \\
\hline $\mathrm{B}$ & $40(37.1)$ & $38(40.0)$ & 0.67 \\
\hline $\mathrm{C}$ & $36(33.3)$ & $29(30.5)$ & 0.67 \\
\hline \multicolumn{4}{|l|}{ SYNTAX score, n (\%) } \\
\hline $0-22$ & $49(45.4)$ & $45(47.4)$ & 0.78 \\
\hline $23-32$ & $59(54.6)$ & $50(52.6)$ & 0.78 \\
\hline \multicolumn{4}{|l|}{ Intra-operative clinical data } \\
\hline Systolic blood pressure, $\mathrm{mmHg}$ & $138.09 \pm 11.08$ & $139.78 \pm 8.12$ & 0.21 \\
\hline Diastolic blood pressure, $\mathrm{mmHg}$ & $90.72 \pm 5.37$ & $89.69 \pm 3.98$ & 0.12 \\
\hline Heart rate, beats/min & $69.76 \pm 5.45$ & $68.56 \pm 4.25$ & 0.08 \\
\hline ECG ST segment elevation $>1 \mathrm{~mm}, \mathrm{n}(\%)$ & $46(42.6)$ & $31(32.6)$ & 0.14 \\
\hline \multicolumn{4}{|l|}{ Blood flow of TIMI score, n (\%) } \\
\hline Level 0-II & $0(0.0)$ & $0(0.0)$ & 1.00 \\
\hline Level III & $108(100.0)$ & $95(100.0)$ & 1.00 \\
\hline Stenosis severity \% & $81.68 \pm 3.08$ & $82.05 \pm 4.23$ & 0.49 \\
\hline Drug-eluting stents, n (\%) & $108(100.0)$ & $95(100.0)$ & 1.00 \\
\hline Time of coronary angiography, min & $69.93 \pm 5.45$ & $68.99 \pm 4.16$ & 0.17 \\
\hline Volume of angiography drug, $\mathrm{ml}$ & $168.00 \pm 19.58$ & $166.35 \pm 14.40$ & 0.49 \\
\hline \multicolumn{4}{|l|}{ Number of stents implanted, $\mathrm{n}(\%)$} \\
\hline $1-2$ & $60(55.6)$ & $56(58.9)$ & 0.63 \\
\hline $3-4$ & $47(43.5)$ & $38(40.0)$ & 0.61 \\
\hline$\leq 5$ & $1(0.9)$ & $1(1.1)$ & 1.00 \\
\hline
\end{tabular}

Results are expressed as the mean \pm standard deviation. AHA, American Heart Association; ACC, American College of Cardiology; ECG, electrocardiography; TIMI, Thrombolysis in Myocardial Infarction.

the clopidogrel group $(\mathrm{P}<0.05)$, suggesting that ticagrelor has a stronger effect on anti-platelet aggregation. Furthermore, the research of Storey et al (29) showed that, compared with clopidogrel, ticagrelor had a much stronger effect on the anti-platelet aggregation irrespective of the loading dose or maintenance dose treatment. The platelet aggregation is the most important cause of ischemic complications among the ACS suffers (30-33); therefore, since ticagrelot has a stronger effect on anti-platelet aggregation, the incidence of recurrent angina in the ticagrelor group was lower compared with the clopidogrel group.

Notably, intensive anti-platelet therapy may result in hemorrhage. In the present study, no significant difference in the rate of hemorrhage occurrence was found between the ticagrelor and clopidogrel groups $(\mathrm{P}=0.91)$. Previously, researchers identified that hemorrhage is the most common adverse event of ticagrelor administration, but most of these events involved mild or moderate bleeding (34). In the current study, 1 case of epistaxis was recorded in each group, as well as 1 case of gum bleeding in the ticagrelor group. The two groups did not report any major hemorrhage events, such as gastrointestinal bleeding. The PLATO study (28) showed that the ticagrelor and clopidogrel groups did not differ significantly with regard to the rates of primary safety end points, including major bleeding $(\mathrm{P}=0.43)$, bleeding requiring red-cell transfusion $(\mathrm{P}=0.96)$, and life-threatening or fatal bleeding $(\mathrm{P}=0.70)$. Therefore, further clinical studies are required to evaluate the bleeding risk of ticagrelor administration.

The current study also showed that dyspnea was more common in the ticagrelor group compared with the clopidogrel group ( $\mathrm{P}=0.03)$. However, the majority of episodes lasted for $<1$ week, and the 6 patients experiencing dyspnea were able to tolerate this event and agreed to continue the treatment. Furthermore, the laboratory test results of the two groups in pre-treatment and after 1, 3, 6 and 12 months of treatment were not significantly different (time-dependent effect, $\mathrm{P}>0.05$ ), which indicates that ticagrelor does not increase the damage on liver and kidney and has no evident effect on the platelet count. 
Table III. Adverse events.

\begin{tabular}{lcrr}
\hline Variable & Group A $(\mathrm{n}=108)$ & Group B (n=95) & P-value \\
\hline Cardiovascular events, n (\%) & & $2(2.1)$ & 0.05 \\
Recurrent angina & $9(8.3)$ & $1(1.1)$ & $>0.99$ \\
Recurrent myocardial infarction & $2(1.8)$ & $1(1.1)$ & $>0.99$ \\
Stent thrombosis & $1(0.9)$ & $3(3.2)$ & 0.88 \\
Stent restenosis & $2(1.8)$ & $0(0.0)$ & $>0.99$ \\
Transient ischemic attack & $0(0.0)$ & $0(0.0)$ & $>0.99$ \\
Mortality & $1(0.9)$ & $6(6.3)$ & \\
Side effects, n (\%) & & $2(2.1)^{\mathrm{b}}$ & 0.03 \\
Dyspnea & $0(0.0)$ & $1(1.1)$ & 0.91 \\
Hemorrhage & $1(0.9)^{\mathrm{a}}$ & $0(0.0)$ & 0.95 \\
Erythra & $0(0.0)$ & $16(16.8)$ & $>0.99$ \\
Diarrhea & $1(0.9)$ & 0.83 \\
Total, n $(\%)$ & $17(15.7)$ & & \\
\hline
\end{tabular}

${ }^{\mathrm{a}}$ Represents epistaxis; ${ }^{\mathrm{b}}$ represents 1 case of epistaxis and the 1 case of gum bleeding.

Table IV. Platelet aggregation rate (\%) in the two groups at different time points.

\begin{tabular}{lcc}
\hline Treatment time & Group A (n=108), \% & Group B (n=95), \% \\
\hline Pre-treatment & $57.33 \pm 9.69$ & $57.85 \pm 7.85$ \\
After 4-week treatment & $37.70 \pm 6.07^{\mathrm{a}}$ & $28.42 \pm 4.88^{\mathrm{a}}$ \\
Difference prior to and following treatment & $19.63 \pm 4.54$ & $29.43 \pm 4.14^{\mathrm{b}}$ \\
\hline
\end{tabular}

${ }^{\text {a }} \mathrm{P}<0.05$, vs. pre-treatment value; ${ }^{\mathrm{b}} \mathrm{P}<0.05$, vs. group A value. Results are expressed as the mean \pm standard deviation.

Table V. Changes in the results of pertinent complete blood count tests.

\begin{tabular}{|c|c|c|c|c|c|}
\hline Variable & $\begin{array}{c}\mathrm{RBC} \\
\left(\mathrm{x} 10^{12} / 1\right)\end{array}$ & $\begin{array}{c}\text { WBC } \\
\left(\times 10^{9} / 1\right)\end{array}$ & $\begin{array}{c}\text { PLT } \\
\left(\times 10^{9} / 1\right)\end{array}$ & $\begin{array}{c}\mathrm{Hb} \\
(\mathrm{g} / \mathrm{l})\end{array}$ & $\begin{array}{c}\mathrm{HCT} \\
(\%)\end{array}$ \\
\hline \multicolumn{6}{|l|}{ Group A (n=108) } \\
\hline Pre-treatment & $4.40 \pm 0.63$ & $7.00 \pm 2.53$ & $200.11 \pm 60.63$ & $134.78 \pm 19.44$ & $41.08 \pm 5.87$ \\
\hline After 1 month & $4.38 \pm 0.69$ & $6.88 \pm 2.15$ & $198.14 \pm 53.68$ & $133.91 \pm 20.69$ & $40.48 \pm 6.08$ \\
\hline After 3 months & $4.41 \pm 0.63$ & $6.93 \pm 2.15$ & $201.14 \pm 60.62$ & $135.96 \pm 19.33$ & $41.83 \pm 5.05$ \\
\hline After 6 months & $4.39 \pm 0.69$ & $6.97 \pm 2.53$ & $199.28 \pm 53.58$ & $132.79 \pm 20.67$ & $39.63 \pm 5.57$ \\
\hline After 12 months & $4.36 \pm 0.69$ & $6.96 \pm 2.14$ & $200.06 \pm 53.42$ & $133.94 \pm 20.22$ & $40.26 \pm 6.72$ \\
\hline \multicolumn{6}{|l|}{ Group B (n=95) } \\
\hline Pre-treatment & $4.31 \pm 0.56$ & $7.29 \pm 2.17$ & $199.38 \pm 51.62$ & $133.64 \pm 16.81$ & $40.96 \pm 4.96$ \\
\hline After 1 month & $4.27 \pm 0.59$ & $6.88 \pm 1.67$ & $196.68 \pm 42.74$ & $132.36 \pm 17.36$ & $40.20 \pm 4.94$ \\
\hline After 3 months & $4.32 \pm 0.54$ & $6.92 \pm 1.67$ & $197.74 \pm 42.77$ & $133.27 \pm 17.19$ & $41.43 \pm 4.51$ \\
\hline After 6 months & $4.29 \pm 0.59$ & $7.15 \pm 2.08$ & $200.35 \pm 51.08$ & $133.93 \pm 16.76$ & $38.96 \pm 4.70$ \\
\hline After 12 months & $4.30 \pm 0.58$ & $7.17 \pm 2.08$ & $199.32 \pm 51.04$ & $134.27 \pm 16.47$ & $39.93 \pm 4.56$ \\
\hline \multicolumn{6}{|l|}{ P-value } \\
\hline Treatment-dependent & 0.29 & 0.62 & 0.88 & 0.75 & 0.60 \\
\hline Time-dependent & 0.39 & 0.11 & 0.57 & 0.19 & 0.06 \\
\hline Interaction & 0.93 & 0.59 & 0.77 & 0.06 & 0.85 \\
\hline
\end{tabular}

Results are expressed as the mean \pm standard deviation. RBC, red blood cell; WBC, white blood cell; PLT, platelet; Hb, hemoglobin; HCT, hematokrit. 


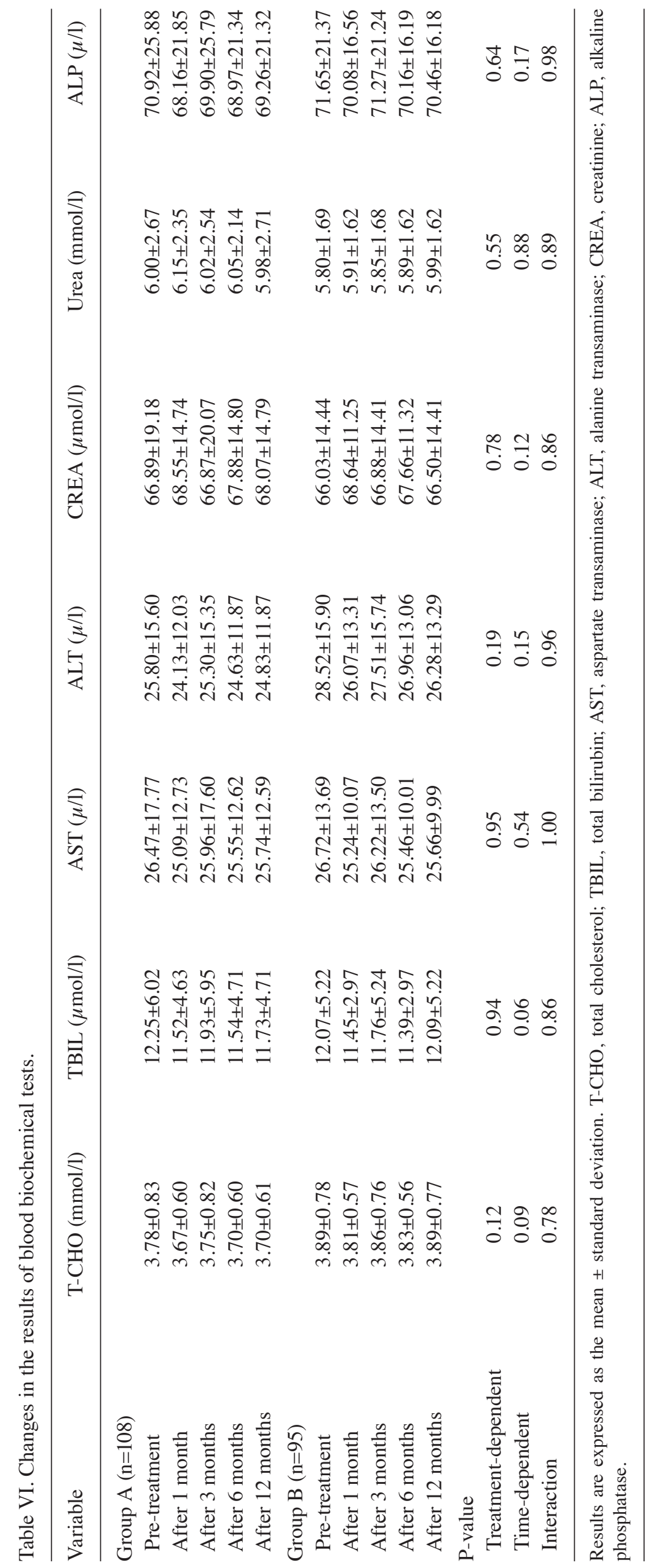


In conclusion, the present study showed that ticagrelor reduced the incidence of adverse cardiovascular events in ACS patients who had received PCI, without increasing the risk of bleeding. However, the present study presented certain limitations, such as a small sample group and short duration of follow-up; thus, the clinical effect and adverse reactions of ticagrelor administration require further confirmation.

\section{Acknowledgements}

The authors would like to thank all the individuals who participated in the study, as well as the doctors and nurses at the Department of Cardiology of The First Affiliated Hospital of Zhengzhou University for their assistance.

\section{References}

1. Anderson JL, Adams CD, Antman EM, Bridges CR, Califf RM, Casey DE Jr, Chavey WE II, Fesmire FM, Hochman JS, Levin TN, et al: 2012 ACCF/AHA focused update incorporated into the ACCF/AHA 2007 guidelines for the management of patients with unstable angina/non-ST-elevation myocardial infarction: A report of the American College of Cardiology Foundation/American Heart Association Task Force on Practice Guidelines. J Am Coll Cardiol 61: e179-e347, 2013.

2. Go AS, Mozaffarian D, Roger VL, Benjamin EJ, Berry JD, Borden WB, Bravata DM, Dai S, Ford ES, Fox CS, et al; American Heart Association Statistica Committee and Stroke Statistics Subcommittee: Heart disease and stroke statistics - 2013 update: A report from the American Heart Association. Circulation 127: e6-e245, 2013.

3. Chase M, Robey JL, Zogby KE, Sease KL, Shofer FS and Hollander JE: Prospective validation of the Thrombolysis in Myocardial Infarction Risk Score in the emergency department chest pain population. Ann Emerg Med 48: 252-259, 2006.

4. Lyon R, Morris AC, Caesar D, Gray S and Gray A: Chest pain presenting to the Emergency Department - to stratify risk with GRACE or TIMI? Resuscitation 74: 90-93, 2007.

5. Hess EP, Perry JJ, Calder LA, Thiruganasambandamoorthy V, Body R, Jaffe A, Wells GA and Stiell IG: Prospective validation of a modified thrombolysis in myocardial infarction risk score in emergency department patients with chest pain and possible acute coronary syndrome. Acad Emerg Med 17: 368-375, 2010.

6. Lee B, Chang AM, Matsuura AC, Marcoon S and Hollander JE: Comparison of cardiac risk scores in ED patients with potential acute coronary syndrome. Crit Pathw Cardiol 10: 64-68, 2011.

7. Karlberg KE, Saldeen T, Wallin R, Henriksson P, Nyguist O and Sylvén C: Intravenous nitroglycerin reduces ischaemia in unstable angina pectoris: A double-blind placebo-controlled study. J Intern Med 243: 25-31, 1998.

8. Kontos MC, Diercks DB, Ho PM, Wang TY, Chen AY and Roe MT: Treatment and outcomes in patients with myocardial infarction treated with acute beta-blocker therapy: Results from the American College of Cardiology's NCDR(®). Am Heart J 161: 864-870, 2011.

9. Moss AJ, Oakes D, Rubison M, McDermott M, Carleen E, Eberly $\mathrm{S}$ and Browm M: Effects of diltiazem on long-term outcome after acute myocardial infarction in patients with and without a history of systemic hypertension. The Multicenter Diltiazem Postinfarction Trial Research Group. Am J Cardiol 68: 429-433, 1991.

10. Yusuf S, Sleight P, Pogue J, Bosch J, Davies R and Dagenais G: Effects of an angiotensin-converting-enzyme inhibitor, ramipril, on cardiovascular events in high-risk patients. The Heart Outcomes Prevention Evaluation Study Investigators. N Engl J Med 342: 145-153, 2000.

11. Cannon CP, Braunwald E, McCabe CH, Rader DJ, Rouleau JL, Belder R, Joyal SV, Hill KA, Pfeffer MA and Skene AM; Pravastatin or Atorvastatin Evaluation and Infection Therapy-Thrombolysis in Myocardial Infarction 22 Investigators: Intensive versus moderate lipid lowering with statins after acute coronary syndromes. N Engl J Med 350: 1495-1504, 2004.
12. Cohen M, Demers C, Gurfinkel EP, Turpie AG, Fromell GJ, Goodman S, Langer A, Califf RM, Fox KA, Premmereur J and Bigonzi F: A comparison of low-molecular-weight heparin with unfractionated heparin for unstable coronary artery disease. Efficacy and Safety of Subcutaneous Enoxaparin in Non-Q-Wave Coronary Events Study Group. N Engl J Med 337: 447-452, 1997.

13. Yusuf S, Zhao F, Mehta SR, Chrolavicius S, Tognoni G and Fox KK; Clopidogrel in Unstable Angina to Prevent Recurrent Events Trial Investigators: Effects of clopidogrel in addition to aspirin in patients with acute coronary syndromes without ST-segment elevation. N Engl J Med 345: 494-502, 2001.

14. James SK, Roe MT, Cannon CP, Cornel JH, Horrow J, Husted S, Katus H, Morais J, Steg PG, Storey RF, et al; PLATO Study Group: Ticagrelor versus clopidogrel in patients with acute coronary syndromes intended for non-invasive management: substudy from prospective randomised PLATelet inhibition and patient Outcomes (PLATO) trial. BMJ 342: d3527, 2011

15. Anderson SD, Shah NK, Yim J and Epstein BJ: Efficacy and safety of ticagrelor: a reversible $\mathrm{P} 2 \mathrm{Y} 12$ receptor antagonist. Ann Pharmacother 44: 524-537, 2010.

16. Kushner FG, Hand M, Smith SC Jr, King SB III, Anderson JL, Antman EM, Bailey SR, Bates ER, Blankenship JC, Casey DE Jr, et al: 2009 focused updates: ACC/AHA guidelines for the management of patients with ST-elevation myocardial infarction (updating the 2004 guideline and 2007 focused update) and ACC/AHA/SCAI guidelines on percutaneous coronary intervention (updating the 2005 guideline and 2007 focused update) a report of the American College of Cardiology Foundation/American Heart Association Task Force on Practice Guidelines. J Am Coll Cardiol 54: 2205-2241, 2009.

17. Vlachojannis GJ, Dimitropoulos G and Alexopoulos D: Clopidogrel resistance: Current aspects and future directions. Hellenic J Cardiol 52: 236-245, 2011.

18. Sofi F, Marcucci R, Gori AM, Giusti B, Abbate R and Gensini GF: Clopidogrel non-responsiveness and risk of cardiovascular morbidity. An updated meta-analysis. Thromb Haemost 103: 841-848, 2010.

19. AstraZeneca: Cardiobascular and metabolic diseases. http://www.astrazeneca.com/medicines/cardiovascular/product/brilinta-brilique. Accessed January 10, 2013.

20. Wallentin L, Becker RC, Budaj A, Cannon CP, Emanuelsson H, Held C, Horrow J, Husted S, James S, Katus H; PLATO Investigators, et al: Ticagrelor versus clopidogrel in patients with acute coronary syndromes. N Engl J Med 361: 1045-1057, 2009.

21. Eagle KA, Guyton RA, Davidoff R, Ewy GA, Fonger J, Gardner TJ, Gott JP, Herrmann HC, Marlow RA, Nugent WC, et al: 1999 ACC/AHA Guidelines for Coronary Artery Bypass Graft Surgery: A Report of the American College of Cardiology/American Heart Association Task Force on Practice Guidelines. J Am Coll Cardiol 34: 1262-1347, 1999.

22. Dolgin M (ed): Nomenclature and Criteria for Diagnosis of Diseases of the Heart and Great Vessels. 9th edition. Lippincott Williams and Wilkins, Philadelphia, PA, pp253-256, 1994.

23. The TIMI Study Group. The Thrombolysis in Myocardial Infarction (TIMI) trial. Phase I findings. N Engl J Med 312: 932-936, 1985.

24. Levine GN, Bates ER, Blankenship JC, Bailey SR, Bittl JA, Cercek B, Chambers CE, Ellis SG, Guyton RA, Hollenberg SM, et al; American College of Cardiology Foundation; American Heart Association Task Force on Practice Guidelines; Society for Cardiovascular Angiography and Interventions: 2011 ACCF/AHA/SCAI Guideline for Percutaneous Coronary Intervention. A report of the American College of Cardiology Foundation/American Heart Association Task Force on Practice Guidelines and the Society for Cardiovascular Angiography and Interventions. J Am Coll Cardiol 58: e44-e122, 2011.

25. Gurbel PA, Antonino MJ and Tantry US: Recent developments in clopidogrel pharmacology and their relation to clinical outcomes. Expert Opin Drug Metab Toxicol 5: 989-1004, 2009.

26. James S, Akerblom A, Cannon CP, Emanuelsson H, Husted S, Katus H, Skene A, Steg PG, Storey RF, Harrington R, et al: Comparison of ticagrelor, the first reversible oral P2Y (12) receptor antagonist, with clopidogrel in patients with acute coronary syndromes: Rationale, design, and baseline characteristics of the PLATelet inhibition and patient Outcomes (PLATO) trial. Am Heart J 157: 599-605, 2009. 
27. Storey RF, Husted S, Harrington RA, Heptinstall S, Wilcox RG Peters G, Wickens M, Emanuelsson H, Gurbel P, Grande P and Cannon CP: Inhibition of platelet aggregation by AZD6140, a reversible oral P2Y12 receptor antagonist, compared with clopidogrel in patients with acute coronary syndromes. J Am Coll Cardiol 50: 1852-1856, 2007.

28. Husted S, Emanuelsson H, Heptinstall S, Sandset PM, Wickens M and Peters G: Pharmacodynamics, pharmacokinetics, and safety of the oral reversible P2Y12 antagonist AZD6140 with aspirin in patients with atherosclerosis: A double-blind comparison to clopidogrel with aspirin. Eur Heart J 27: 1038-1047, 2006.

29. Storey RF, Angiolillo DJ, Patil SB, Desai B, Ecob R, Husted S, Emanuelsson H, Cannon CP, Becker RC and Wallentin L: Inhibitory effects of ticagrelor compared with clopidogrel on platelet function in patients with acute coronary syndromes: The PLATO (Platelet inhibition and patient outcomes) PLATELET substudy. J Am Coll Cardiol 56: 1456-1462, 2010.

30. Tantry US, Bliden KP and Gurbel PA: Resistance to antiplatelet drugs: Current status and future research. Expert Opin Pharmacother 6: 2027-2045, 2005.
31. Gurbel PA, Bliden KP, Hayes KM and Tantry U: Platelet activation in myocardial ischemic syndromes. Expert Rev Cardiovasc Ther 2: 535-545, 2004.

32. Gurbel PA, Bliden KP, Zaman KA, Yoho JA, Hayes KM and Tantry US: Clopidogrel loading with eptifibatide to arrest the reactivity of platelets: Results of the clopidogrel loading with eptifibatide to arrest the reactivity of platelets (CLEAR PLATELETS) study. Circulation 111: 1153-1159, 2005.

33. Gurbel PA, Bliden KP, Samara W, Yoho JA, Hayes K, Fissha MZ and Tantry US: Clopidogrel effect on platelet reactivity in patients with stent thrombosis: Results of the CREST study. J Am Coll Cardiol 46: 1827-1832, 2005.

34. Wang K, Zhou X, Huang Y, Khalil M, Wiktor D, van Giezen JJ and Penn MS: Adjunctive treatment with ticagrelor, but not clopidogrel, added to tPA enables sustained coronary artery recanalisation with recovery of myocardium perfusion in a canine coronary thrombosis model. Thromb Haemost 104: 609-617, 2010 . 